\title{
liderazgo pedagógico competente
}

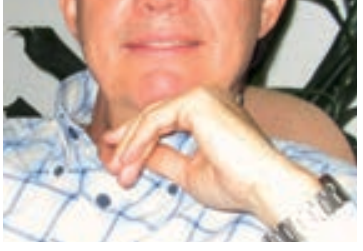

Vicente Hernández Franco Director
"Como educadores, lo que sois se comunica más significativamente que lo que hacéis o decís». KolvenbaCH, H. P. (Villa Cavalletti, I993). La pedagogía ignaciana hoy.

os últimos resultados del Informe PISA han situado a los adolescentes españoles por debajo de la media de la OCDE en habilidades para solucionar problemas significativos de la vida cotidiana. Los análisis de estas pruebas ponen de manifiesto que la "calidad docente" constituye un factor clave en los resultados de aprendizaje de los estudiantes, tal como es evaluado en las pruebas PISA, y para mejorar las puntuaciones del conjunto de nuestro país parece que sería necesario acometer algunas reformas en la selección, formación y desarrollo de la carrera profesional de nuestros maestros y profesores.

Aunque la instrucción de los jóvenes de quince años que realizan las pruebas PISA se encuentra a cargo de los profesores especialistas de las distintas materias de secundaria, algunas interpretaciones atribuyen las deficiencias en las calificaciones que obtiene nuestro país al "bajo nivel de conocimientos" de los maestros y las maestras que se forman en España. Socialmente se ha abierto un debate, cada vez más presente en los medios, sobre qué jóvenes seleccionar para estudiar Magisterio en nuestras universidades. ¿Debería sólo admitirse a los candidatos más competentes con un historial de calificaciones escolares de excelencia, como los que acceden a la carrera de medicina? Como sabemos, tener muchos conocimientos de una materia no garantiza saber cómo enseñarla y mucho menos lo que los alumnos lleguen a aprender; por tanto, ¿cómo asegurarnos de que acceden a los estudios de Magisterio también los excelentes en "vocación" educadora, con una historia de vida probada con experiencias de servicio y ayuda a los demás? ¿Se puede encontrar un equilibrio entre ambos criterios?

El debate está servido y la respuesta se tendrá que abrir camino en un plazo breve. Desde estas páginas queremos recordar lo que nuestra experiencia y tradición pedagógica nos enseña: contar con un estudiante "vocacional" es crucial e insustituible para llegar a formar un maestro auténtico. Podemos asegurar que si la formación que recibe es la adecuada, el estudiante de Magisterio descubre progresivamente el ejercicio de esta profesión como una "vocación", experimentada como una "llamada interior" que configura su identidad personal e integra y desarrolla más plenamente su proyecto vital. El estudiante de Magisterio que termine graduándose habrá visto forjada y probada su llamada "vocacional" durante sus años de formación, y se encontrará preparado para finalmente asumir en su entrega vital a su profesión un modo congruente de "ser-para-sí" y de "ser-para-el-otro" que le llevará a ser percibido por sus alumnos, familias y colegas como hombre/mujer para los demás, y también como hombre/mujer con los demás.

Para el maestro y el profesor con vocación, el oficio de enseñar constituye el núcleo de su acción profesional como educador. Desde su "estilo personal" busca siempre aquellos métodos y recursos que permitan a sus alumnos progresar y alcanzar cada vez mejores resultados de aprendizaje. Así, sólo desea y elige lo que la evidencia pedagógica contrastada muestra que más conduce a sus alumnos, según sus talentos, a alcanzar los mejores resultados que puedan lograrse en su formación integral.

Cuando hablamos de la educación de nuestros niños, hablamos de cómo construir nuestro futuro como sociedad. Vaya desde aquí el reconocimiento a todos los jóvenes que desde vuestra vocación por los estudios de Magisterio, seguís queriendo recibir una buena formación para llegar a ser el mejor maestro que vuestros alumnos puedan tener. Los maestros y los profesores, como líderes pedagógicos de una comunidad social, somos verdaderamente competentes cuando avanzamos y damos respuesta a los desafíos que nos proponen las vidas de nuestros alumnos al entrar cada mañana en el aula. Somos verdaderos líderes cuando la sociedad a la que servimos nos encuentra siempre preparados para atender a las tareas que como comunidad profesional nos correspondan. Seremos valorados mientras continuemos buscando nuevos caminos y avancemos hacia donde nos impulsa nuestro corazón de educadores, para realizar nuestro último y más profundo deseo: contribuir al bienestar y la felicidad de nuestros alumnos. ¡Vosotros, los líderes pedagógicos competentes, sois insustituibles! 